14

\title{
Активация нейромедиаторов мозга животных интерференционными транскраниальными токами
}

\author{
(c) Y. Katsnelson, ${ }^{1}$ A.В. Ильинский, ${ }^{2}$ Е.Б. Шадрин ${ }^{2}$ \\ ${ }^{1}$ Brain Advance Wellness Technologies, \\ 3801 Stump Rd, Doylestown, PA 18902, USA \\ ${ }^{2}$ Физико-технический институт им. А.Ф. Иоффре РАН, \\ 194021Санкт-Петербург, Россия \\ e-mail: shadr.solid@mail.ioffe.ru
}

Поступило в Редакцию 08 июня 2021 г.

В окончательной редакции 29 июля 2021 г.

Принято к публикации 30 июля 2021 г.

\begin{abstract}
Предложен новый метод транскраниальной электромагнитной стимуляции мозга млекопитающих. Метод основан на интерференции токов, вызванных высокочастотными ортогональными колебаниями электрических полей и промодулированных меандрами низкой частоты. Эффективность метода обоснована результатами экспериментов по стимуляции мозга крыс и кроликов.
\end{abstract}

Ключевые слова: электромагнитная стимуляция, интерференция, альфа-ритмы, тета-ритмы, серотонин, бета-эндорфины, нейрон.

DOI: $10.21883 /$ JTF.2021.12.51773.177-21

\section{Введение}

В мировой литературе представлено немало экспериментального материала по проблеме влияния электрических и магнитных полей на биологические процессы, протекающие в живом организме [1-3]. Особое место в этой проблеме занимает транскраниальная электромагнитная стимуляция (ТЭС) мозга млекопитающих, представляющая собой процесс воздействия на мозг электрических полей, формируемых либо контактным [4], либо бесконтактным методами [5]. В первом случае воздействие осуществляется путем наложения на кожный покров головы млекопитающего наружных (или вживленных под кожу или в структуры мозга) электродов, к которым подводится переменное электрическое напряжение, в результате чего между электродами протекают одновременно дрейфовый электрический ток и ток смещения, при этом в общем случае оба вида тока текут как внутри черепной коробки, так и по наружным кожным покровам головы. Во втором случае токовое воздействие осуществляется путем помещения мозга в высокочастотное электромагнитное поле, которое вызывает протекание в наружных покровах головы индукционных токов ввиду наличия высокой электрической проводимости кожи, определяемой разветвленной сетью микрокапилляров. Микрокапилляры содержат плазму крови с высокой электропроводностью, клеточные элементы и эритроцитарные агрегаты, которые сквозь стенки сосудов взаимодействуют посредством транспортных белков с цереброспинальной жидкостью, циркулирующей в полостях пространства Вирхова-Робина вокруг микрокапилляров [6].

Не вызывает сомнения то, что ТЭС в большинстве случаев оказывает благотворное влияние на клиниче- ское и психосоматическое состояние организма, снижая интенсивность болевого синдрома, уменьшая выраженность депрессивного синдрома, панических атак и некоторых других психоэмоциональных нарушений. Однако процедура изучения физических причин, обусловливающих протекание описанных процессов, весьма далека от завершения, что определяет неослабевающий интерес к подобного рода исследованиям. В настоящее время является общепринятым то, что выработка серотонина и бета-эндорфинов антиноцицептивными структурами мозга под действием ТЭС способна понизить уровень болевого синдрома и психоэмоциональных нарушений, приводя к нормализации нейрогуморального дисбаланса.

Целью настоящей работы является описание более эффективного по сравнению с существующими алгоритма ТЭС, а также анализ результатов экспериментальных исследований влияния ТЭС, использующей усовершенствованный алгоритм, на активацию серотонинэргических и бетаэндорфинэргических структур мозга лабораторных животных.

Отправной точкой разработки нового алгоритма послужила информация $[7,8]$ о том, что повышенное содержание бета-эндорфинов в структурах мозга кролика проявлялось максимально при использовании для ТЭС частоты повторения стимулирующих импульсов, равной $78 \mathrm{~Hz}$.

Новый предлагаемый в настоящей работе алгоритм ТЭС предусматривает, помимо стимуляции серотонинэргических и бета-эндорфинэргических структур мозга, также возможность активации структур, связанных с $\alpha$ - и $\theta$-ритмами мозга, поскольку нейрофизиологами установлена корреляция между увеличением амплитуды $\alpha$ - и $\theta$-ритмов мозга и снижением выраженности симп- 
томов депрессии [9]. Сказанное диктует необходимость использования при совершенствовании методики ТЭС одновременно с применением частоты $78 \mathrm{~Hz}$ также частотного диапазона от 5 до $14 \mathrm{~Hz}$, стимулирующего $\alpha$ - и $\theta$-ритмы мозга.

\section{1. Методика эксперимента}

\section{1. Техническая часть ТЭС}

В данном разделе сначала описывается техническая (аппаратурная) часть методики, а вслед за этим методическая (биофизическая) часть ТЭС мозга животных.

Новый алгоритм ТЭС сводится к формированию в мозге животного двух взаимно перпендикулярных по направлению распространения переменных токов, интерферирующих друг с другом в области пересечения трубок токов. Предлагаемый алгоритм ТЭС призван более эффективно по отношению к общеизвестным методам повышать интенсивность выработки серотонина и бета-эндорфинов в тканях мозга за счет процесса интерференции токов в прицельно выбранных для стимуляции глубоких структурах мозга.

Для обеспечения эффектов интерференции в новом алгоритме ТЭС использованы 4 электрода в виде пар: одна пара обеспечивает наличие трубки тока в базальном направлении лоб-затылок, а другая пара электродов налагается на область мастоидальных отростков, формируя вторую трубку тока, перпендикулярную первой. Все 4 электрода вживлялись под кожу головы животного, причем в ходе контрольных опытов устанавливалось отсутствие влияния на экспериментальные результаты стрессорной реакции, возникающей как следствие хирургического вмешательства. Конфигурация электродов выбиралась таким образом, чтобы все электроды лежали приблизительно в одной плоскости. Использование двух пар электродов позволяло создать в мозге животного две пересекающиеся трубки тока с контролируемой зоной пересечения, в которой возникала интерференция токов, возбуждаемых в тканях мозга. Длина высокочастотной электромагнитной волны, играющей роль несущей, составляет несколько метров. Это показал простейший расчет (см. ниже) с использованием литературных значений диэлектрической проницаемости тканей мозга, из чего следует, что колебания токов в области интерференции суммируются, попеременно усиливая или ослабляя во времени друг друга и пространственно равномерно покрывая всю интерференционную зону. При этом для модуляции высокочастотного несущего напряжения нами использовались биполярные меандры с двумя различными частотами повторения - 88 и $68 \mathrm{~Hz}$. Выбор данных частот был обусловлен тем, что, поскольку в области интерференции возникают колебания на частоте, равной полусумме модулирующих частот, а также низкочастотные биения, область интерференции подвергается воздействию электромагнитных колебаний с частотой полусуммы $78 \mathrm{~Hz}$ и низкочастотных биений $5-14 \mathrm{~Hz}$.
Колебание с частотой $78 \mathrm{~Hz}$ выполняло в процессе ТЭС функции, описанные выше, тогда как низкочастотные биения соответствовали $\alpha$ - и $\theta$-ритмам мозга животного. Электромагнитное воздействие с частотой $78 \mathrm{~Hz}$ способствует повышению в мозге животных концентрации таких нейромедиаторов, как бета-эндорфины и серотонин. Наряду с этим, электромагнитные низкочастотные биения также обеспечивают дополнительное повышение концентрации указанных нейромедиаторов.

Литературные данные [10] свидетельствуют о том, что нейтрализация судорожной активности, обусловленной, в частности, ранее разработанными режимами ТЭС, может быть достигнута применением слабого постоянного тока, протекающего наряду с переменным в той же электрической цепи. Поэтому для эффективной ТЭС мозга, не сопровождаемой побочными явлениями, переменное напряжение должно подаваться с помощью схемы с постоянным электрическим смещением, обеспечивающим формирование слабой постоянной составляющей электрического тока, протекающего сквозь мозг животного между теми же электродами, что и импульсная составляющая [11].

Другой возможностью блокировки судорог является использование биполярного несимметричного меандерного напряжения с частотой повторения $78 \mathrm{~Hz}$, модулирующего высокочастотное несущее напряжение. В настоящей работе мы воспользовались именно этой возможностью, применив в виде несущего биполярное несимметричное импульсное напряжение частотой $500 \mathrm{kHz}$. Импульсные электрические поля с частотой $500 \mathrm{kHz}$ эффективно проникают в глубину мозга, поскольку слабо экранируются ионной поляризацией тканей. Кроме того, биполярные импульсы частоты $500 \mathrm{kHz}$, как показывает простой расчет, формируют постоянную токовую составляющую в соответствии с электрическими характеристиками тканей мозга.

Рассмотрим электрическую схему ТЭС мозга более подробно.

Блок-схема устройства содержит три генератора переменного напряжения в виде амбиполярных меандров (рис. 1), а именно генератор напряжения с несущей частотой $500 \mathrm{kHz}$ и два модулирующих несущую низкочастотных генератора с частотами $88 \mathrm{~Hz}$ (питает базальные электроды) и $68 \mathrm{~Hz}$ (питает мастоидальные электроды).

Длительность, скважность и форма импульсов также представлены на рис. 1. Каждая из пар электродов состоит из двух металлических пластин, соединенных с одним из двух каналов. Блок-схема содержит также управляющий компьютер и контрольный монитор. Годограф вектора суммарного электрического поля $\mathbf{E}$ высокой частоты в тканях мозга представлен на рис. 2, a.

Высокочастотный биполярный меандр с частотой повторения $500 \mathrm{kHz}$ имеет скважность $1 / 4$ и амплитуду короткого импульса $24 \mathrm{~V}$, а более длинного $-8 \mathrm{~V}$ (рис. 1). Длина электромагнитной волны 


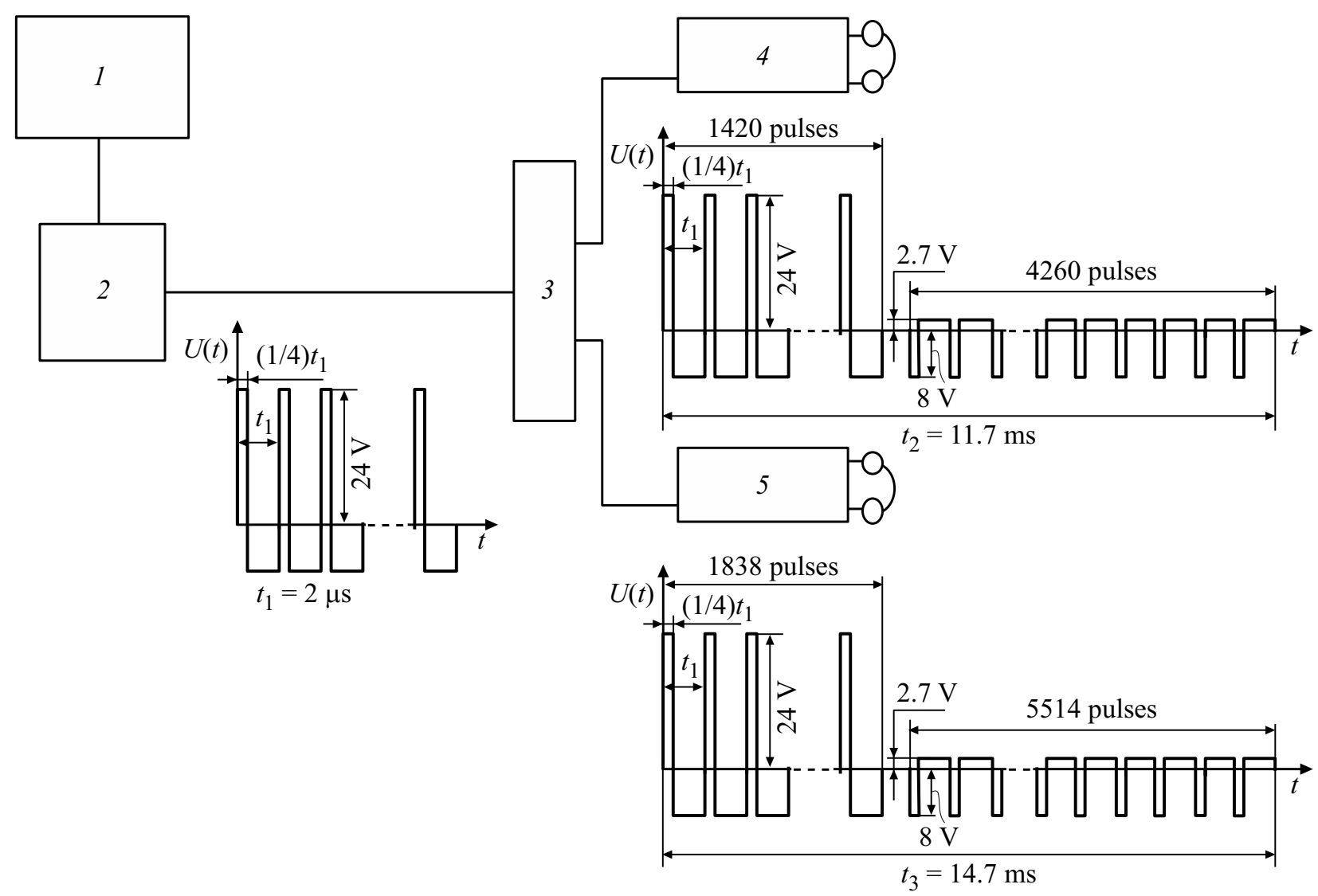

Рис. 1. Блок-схема устройства ТЭС и эпюры напряжений. 1 - управляющий компьютер и контрольный монитор, $2-$ генератор $500 \mathrm{kHz}, 3$ - сепаратор, 4,5 - генераторы 88 и $68 \mathrm{~Hz}$ с инверторами и электродами.
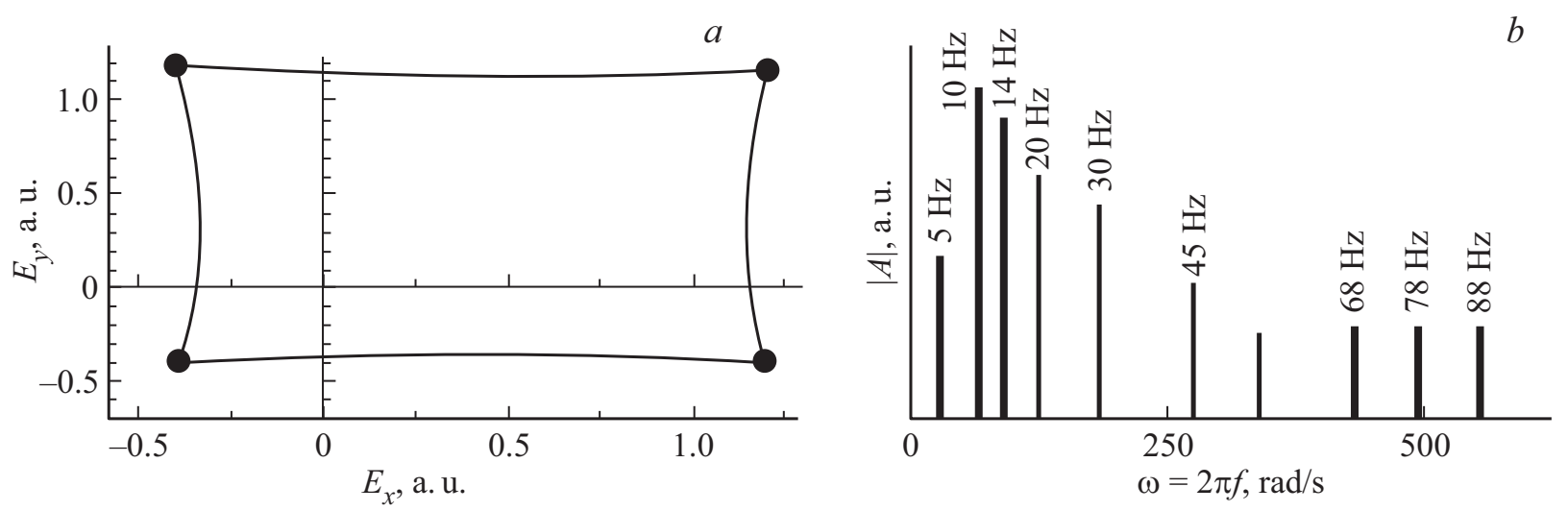

Рис. 2. $a$ - изменение годографа вектора напряженности высокочастотного электрического поля $\mathbf{E}$ за время одного периода $t_{1}=2 \mu \mathrm{s}$. Годограф содержит все направления $\mathbf{E}$, однако основные направления $\mathbf{E}$ отмечены точками в углах годографа, поскольку напряжение к электродам прикладывается в виде прямоугольных меандров. Годограф смещен в положительном направлении по осям координат из-за отличия величин положительных и отрицательных амплитуд высокочастотного меандра. $b-$ модуль амплитуд фурье-гармоник низкочастотного сигнала, полученного в результате векторного сложения электрических полей для двух меандров с частотами 88 и $68 \mathrm{~Hz}$.

в вакууме, соответствующая основной синусоидальной гармонике высокочастотной несущей, составляет $\lambda=c / v=3 \cdot 10^{8} /\left(5 \cdot 10^{5}\right)=600 \mathrm{~m}$. В экранирующей электрическое поле среде, т.е. в мозге животного, она меньше в $n$ раз $-\lambda / n$, где $n=(\varepsilon)^{1 / 2}=50$, а $\varepsilon=2500-$ низкочастотная диэлектрическая проницаемость тканей мозга животного. С учетом сказанного длина волны оказывается равной $12 \mathrm{~m}$, т. е. намного большей поперечных размеров головы животного. Вследствие этого возникающая в мозге животного интерференцион- 
ная картина представляет собой однородную пространственно ограниченную область, в которой происходит сложение колебаний и совершаются электрические пульсации, т. е. биения колебаний электромагнитных полей и токов.

Поэтому в дальнейшем речь будет идти о колебательном изменении напряженностей электрических полей и плотностей протекающих токов, равномерно перекрывающих весь пространственно-ограниченный объем зоны пересечения ортогональных трубок тока. Из сказанного следует, что, изменяя расположение электродов на коже головы, можно управлять пространственным положением зоны интерференции, активируя различные участки мозга.

Следует заметить, что временная зависимость амплитуды плотности токов не совпадает с временной зависимостью амплитуды приложенного биполярного меандра напряжений. Дело в том, что голова животного обладает электрическим сопротивлением, которое в общем случае носит комплексный характер. Расчет комплексным методом простейшей эквивалентной электрической схемы мозга животного с наложенными электродами приводит к выявлению существенных различий формы колебаний плотности тока и приложенного напряжения. Такая эквивалентная схема содержит электрическую емкость, а также два сопротивления: зарядное и разрядное, имитирующие проводимость тканей мозга. Емкость обусловлена парой электродов, между которыми располагается среда с достаточно высоким значением диэлектрической проницаемости $\varepsilon=2500$ (плотные ткани мозга и базальные цистерны, заполненные ликвором). Зарядное сопротивление имитирует контактное сопротивление кожи головы и костей черепа животного, разрядное сопротивление, подключенное параллельно емкости, имитирующей способность тканей мозга к экранировке внешнего поля, представляет собой электрическое сопротивление внутренних тканей мозга. Постоянная времени $\tau$ такой схемы определяется выражением $\tau=\left(C R_{\text {charge }} R_{\text {discharge }}\right) /\left(R_{\text {charge }}+R_{\text {discharge }}\right)$ и составляет по нашим оценкам $6 \mu \mathrm{s}\left(C=100 \mathrm{pF}, R_{\text {charge }}=5 \cdot 10^{4} \Omega\right.$, $R_{\text {discharge }}=10^{5} \Omega$ ), что существенно больше периода высокочастотного напряжения $1 / f=(1 / 5) \cdot 10^{-5} \mathrm{~s}=2 \mu \mathrm{s}$. Сказанное означает, что короткие по времени импульсы меандра будут проинтегрированы в процентном отношении значительно эффективнее, чем протяженные во времени импульсы противоположной полярности, т.е. при интегрировании в RC-цепи изначальное равенство площадей импульсов противоположной полярности изменится в пользу протяженной во времени части биполярного импульса. Другими словами, произойдет значительное смещение интегральной средней линии биполярного меандра в сторону его широких импульсов, благодаря чему, наряду с переменной составляющей тока, между электродами потечет постоянный ток, протекающий в одном преимущественном направлении.

Следует также учесть, что сложение колебаний электромагнитных полей в области пересечения ортогональ- ных трубок тока приведет к появлению в этой области серии плоских фигур Лиссажу, расположенных в нескольких слоях, параллельных плоскости электродов. Вид этих фигур, определяющих направление суммарного вектора тока и вектора электромагнитного поля, определяется разностью фаз между колебаниями одноименных фурье-гармоник (рис. 2, $b$ ) складывающихся ортогональных токов и электромагнитных полей.

Модуляция высокочастотного напряжения осуществлялась в примененной нами электрической схеме биполярными меандрами напряжения низкой частоты $(88$ и $68 \mathrm{~Hz})$ со скважностью 4. В результате модуляции в мозге животного, наряду с однонаправленными взаимно ортогональными токами, протекали взаимно ортогональные токи переменной полярности. Последние в области пересечения трубок токов возбуждали в основном низкочастотные биения колебаний. Форма фигур Лиссажу и их изменения во времени весьма сложны для анализа в силу многофакторности протекающих процессов: наличие разных частот модуляции, сложный закон изменения во времени фазовых сдвигов между различными фурьегармониками, генерируемыми всей совокупностью источников напряжения, сложное разветвление в мозгу животного токов на отдельные „потоки“ и т.п. Тем не менее анализ показывает, что главными частотами низкочастотных колебаний являются полусумма частот 68 и $88 \mathrm{~Hz}$, модулирующих высокочастотную несущую, а именно $78 \mathrm{~Hz}$ и низкочастотные биения диапазона 5-14 Hz, совокупность которых представляет собой набор оптимальных частот для эффективной ТЭС мозга.

Отметим положительные технические моменты реализации предлагаемого в настоящей работе интерференционного алгоритма ТЭС мозга животных:

1) Использование двух пар электродов, обеспечивающих наличие процесса суммирования в ограниченной по объему зоне, снижает величину общего тока, протекающего через мозг животного. Причина этого состоит в перекачке в рабочую зону энергии из незахватываемых зоной интерференции областей мозга, согласно принципам когерентного интерференционного суммирования.

2) Выбор положения электродов на поверхности кожного покрова позволяет менять пространственное расположение ограниченной по объему области пересечения взаимно перпендикулярных трубок тока внутри головы животного, что расширяет исследовательские возможности.

3) Использование двух пар электродов с напряжениями различных частот $(88$ и $68 \mathrm{~Hz})$ модуляции амплитуды высокочастотного напряжения позволяет в одной процедуре воздействия генерировать эффективные для ТЭС частоты колебаний $78 \mathrm{~Hz}$ и периодические пульсации тока в диапазоне низких частот 5-14 Hz.

4) Использование несимметричного высокочастотного биполярного меандра позволяет, наряду с переменными токами, обеспечить возможность протекания в тканях мозга однонаправленных токов, способствующих по- 
давлению очагов судорожной активности центральной нервной системы животного.

5) Быстропеременные биения в виде разнонаправленных фигур Лиссажу задействуют разные микроучастки мозга в пределах области интерференции, что уменьшает „привыкание“ тканей мозга к ТЭС. В ранних вариантах реализации ТЭС привыкание вынуждало непрерывно повышать рабочее напряжение на электродах с целью противодействия снижению эффективности ТЭС в результате действия „компенсационного“ механизма привыкания [11].

6) Изменение направления в пространстве векторов токов и полей (фигуры Лиссажу) позволяет предотвратить электрическую ионную поляризацию ликвора базальных цистерн. Процесс поляризации вынуждал, во избежание эффекта „привыкания“, менять полярность постоянного тока через каждые 15-20 min ТЭС. Использование интерференции токов позволяет также снизить такой негативный эффект, как неконтролируемый спонтанный рост амплитуды биполярных импульсов в течение первых 5-10 min ТЭС с их падением в течение следующих 5-10 min.

\section{2. Биофизическая часть методики ТЭС мозга животных}

Наиболее удобным способом подтверждения эффективности предлагаемого нового алгоритма стимуляции является экспериментальное тестирование воздействия интерференционного варианта ТЭС на мозг таких лабораторных животных, как крысы и кролики. В настоящем разделе рассматриваются два варианта методики: выработка условного рефлекса (УР) избегания электрического удара у крыс и подавление болевого синдрома (снижение болевой чувствительности) у кроликов.

\subsection{1. Деление крыс на группы. Технология вы-} работки УР В экспериментах использовались 4 группы половозрелых крыс (самцы линии Вистар массой около $130 \mathrm{~g}$ ), причем в каждой группе было по 11 животных. Животные были распределены по экспериментальным группам с помощью процедуры рандомизации.

Первая группа являлась контрольной; для нее оценивалось развитие устойчивого УР избегания электрического удара на интактных крысах.

Вторая группа также была контрольной, но отличалась от первой тем, что животные в ней имели две пары имплантированных под кожу головы электродов: лобно-затылочный и заушный каналы микротокового воздействия. Имплантация электродов осуществлялась под ингаляционным наркозом (4.5\% фторотан, кислород 11 /min, продолжительность $5 \mathrm{~min})$. В этой группе эксперименты производились через сутки после имплантации электродов с целью нивелирования болевого синдрома процесса вживления.
У животных третьей группы непосредственно перед процедурой выработки УР осуществлялась ТЭС в течение $30 \mathrm{~min}$.

Наконец, животным четвертой группы за $30 \mathrm{~min}$ до начала ТЭС вводился китрил, а затем ТЭС осуществлялась в течение $30 \mathrm{~min}$. Введение китрила диктовалось тем, что этот препарат является блокатором серотонина. Результаты экспериментов с животными третьей и четвертой группы однозначно показали, что ТЭС мозга препятствует формированию УР. Китрил блокирует чувствительность серотонинэргических рецепторов, что проявляется в более быстром формировании УР даже при проведении ТЭС мозга. Обоснуем это утверждение более подробно.

Процедура выработки УР у крыс заключается в следующем. Животное помещается в испытательный вольер. На лапки животного подается серия импульсов напряжения одновременно со звонком (серия из 70 импульсов амплитудой $100 \mathrm{mV}$ и длительностью $8 \mathrm{~ms}$, частота звука $50 \mathrm{~Hz}$ с уровнем громкости 50-60 dB). Животное практически мгновенно вспрыгивает на „электробезопасную“ полочку вольера. Но при подаче после этого одного лишь звонка без электроудара впрыгивания не происходит. Тогда комбинированное воздействие электроудара и звонка повторяется $N$ раз. После этого подается только звонок, и животное вспрыгивает на полочку, но не каждый раз. Вычисляется процентное отношение $\alpha=\left(\Delta n / n_{0}\right) \cdot 100 \%$ числа $\Delta n$ проверочных впрыгиваний только по звуку без электроудара к общему числу по подач звука. Оказалось, что при $N=3$ в среднем $\alpha=30 \%$. После этого число $N$ увеличивали до значения $N=N_{s t}$, пока не будет достигнуто $\alpha=90 \%$, что и предлагалось считать завершением формирования устойчивого УР избегания болевого воздействия.

\subsection{2. Технология определения времени избега-} ния болевого раздражения. Деление кроликов на группы Поскольку известно [12], что ТЭС мозга способна активировать не только серотонинэргические, но и бетаэндорфинэргические структуры мозга, в настоящей работе описаны также результаты экспериментов по тестированию усовершенствованного интерференционного алгоритма ТЭС на лабораторных кроликах.

До начала экспериментов животные подвешивались в специальном гамаке с прорезями для конечностей, пребывание в котором в течение $3-4$ h не приводило к возникновению иммобилизационной аналгезии. Для термического раздражения использовалось радиационное тепло пучка света. В этом методе на нос обездвиженного кролика в момент времени $t_{0}$ проецировалось пятно интенсивного ИК света галогенной лампы, которое вызывало болевое раздражение. Спустя промежуток времени $\Delta t=t_{R}-t_{0}(\Delta t-$ время избегания) кролик реагировал на болевое раздражение отдергиванием головы. Временная точка $t_{R}$ фиксировалась как момент реакции кролика, причем положение этой точки на временной шкале 

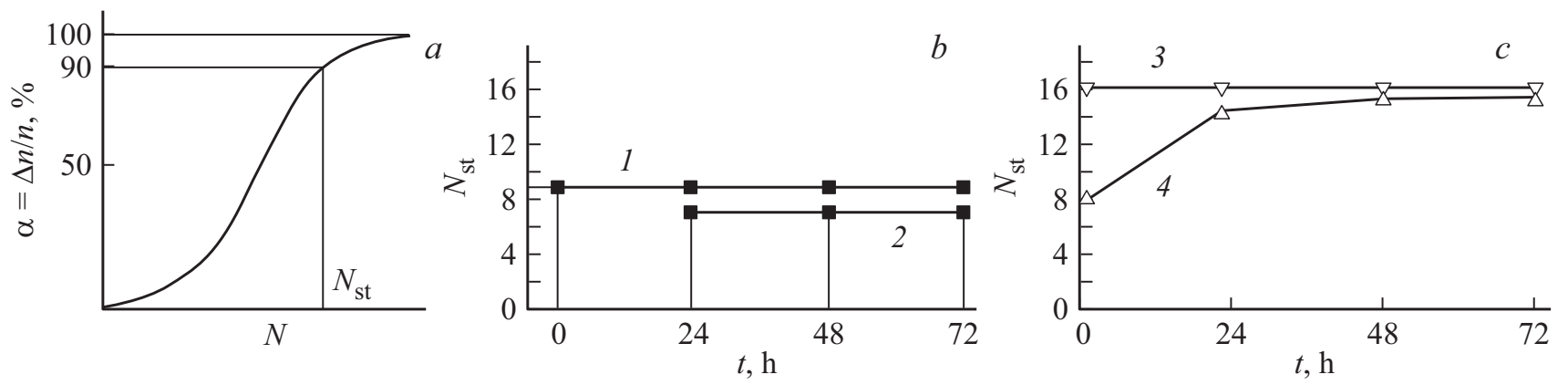

Рис. 3. $a$ - зависимость усредненного процента $\alpha$ числа проверочных реализаций выработанного УР избегания болевого воздействия от $N$ - числа повторений воздействия одновременно импульсом тока и звуковым сигналом при экспериментах с крысами. $b$ необходимое для выработки устойчивого УР число повторений $N_{s t}$ одновременного воздействия импульсом тока и звуковым сигналом для двух групп крыс: без электродов -1 и с вживленными электродами -2 . $c-$ сопоставление чисел повторения $N_{s t}$ для выработки устойчивого УР после кратковременной ТЭС $(30 \mathrm{~min})$ для двух групп крыс: без китрила -3 и с введенным китрилом - 4 .

оказывалось зависимым от различных воздействий на его организм (в частности, от частоты ТЭС)

В экспериментах использовались 4 группы кроликов, причем в каждой группе было по 12 животных. Животные были распределены по экспериментальным группам с помощью процедуры рандомизации, т.е. случайным образом. Всего в экспериментах было использовано 48 половозрелых кроликов-самцов новозеландской породы.

Первая контрольная группа не подвергалась никакому стрессорному воздействию. В ней измерялось $\Delta t-$ время реакции избегания болевого раздражения.

Вторая контрольная группа отличалась от первой тем, что животные в ней имели две пары имплантированных под кожу головы электродов: лобно-затылочный (саггитальный) и заушный (мастоидальный) каналы микротокового воздействия. Имплантация электродов осуществлялась под ингаляционным наркозом (4.5\% фторотан, кислород $11 / \mathrm{min}$, продолжительность операции $5 \mathrm{~min})$. Во второй контрольной группе эксперименты по измерению времени реакции кролика на термическое болевое воздействие производились через сутки после имплантации электродов. Это было сделано с целью нивелирования болевого синдрома, вызванного процессом вживления. При статистическом анализе в группе с вживленными электродами не было выявлено статистически значимой разницы во времени между моментом включения источника тепла и реакцией избегания болевого воздействия по сравнению с группой без электродов.

Третья группа животных использовалась для измерения степени повышения болевого порога (снижения болевой чувствительности) на фоне ТЭС. Эта группа была разбита на две подгруппы, в одной из которых эксперименты производились на стандартном трехэлектродном ТЭС приборе марки TESA, а в другой - на модифицированном четырехэлектродном интерференционном приборе.
Животным четвертой группы за 30 min до начала ТЭС мозга вводился налоксон - блокатор чувствительности бета-эндорфинэргических рецепторов [13]. Следует отметить, что, поскольку анальгезия является одним из наиболее важных результатов прямой стимуляции антиноцицептивной системы [14], в настоящей работе обезболивание использовалось в качестве индикатора активации бета-эндорфинэргических систем во время и после ТЭС мозга.

\section{2. Результаты эксперимента}

\section{1. ТЭС мозга крыс}

На рис. 3, а приведен график зависимости $\alpha$ от числа повторений $N$ операции „электроудар + подача звука“. По этому графику определяется величина $N_{s t}$ при достижении величины $\alpha=90 \%$.

На рис. 3, $b$ приведены значения Nst для животных первой и второй групп, т.е. без электродов 1 и с вживленными электродами 2. Из рисунка видно, что через сутки после вживления под наркозом электродов под кожу головы животного нет статистически значимых отличий $N_{s t}$ для контрольной группы животных от $N_{s t}$ для животных со вживленными электродами (ход зависимости $N_{s t}$ для обеих групп почти совпадает). Не были выявлены также возможные воспаления зон хирургического вмешательства. Эти предварительные результаты свидетельствуют о возможности проведения ТЭС мозга животных с вживленными электродами.

На рис. 3,c приведены значения $N_{s t}$ для третьей и четвертой групп животных со вживленными электродами. Животным третьей группы через сутки после вживления электродов осуществлялась ТЭС в течение $30 \mathrm{~min}$. При этом обнаружена блокировка процесса выработки УР. То есть при ТЭС значение $N_{s t}$ поднималось со значения $N_{s t}=8$ без ТЭС (рис. $\left.3, b 2\right)$ до значения 

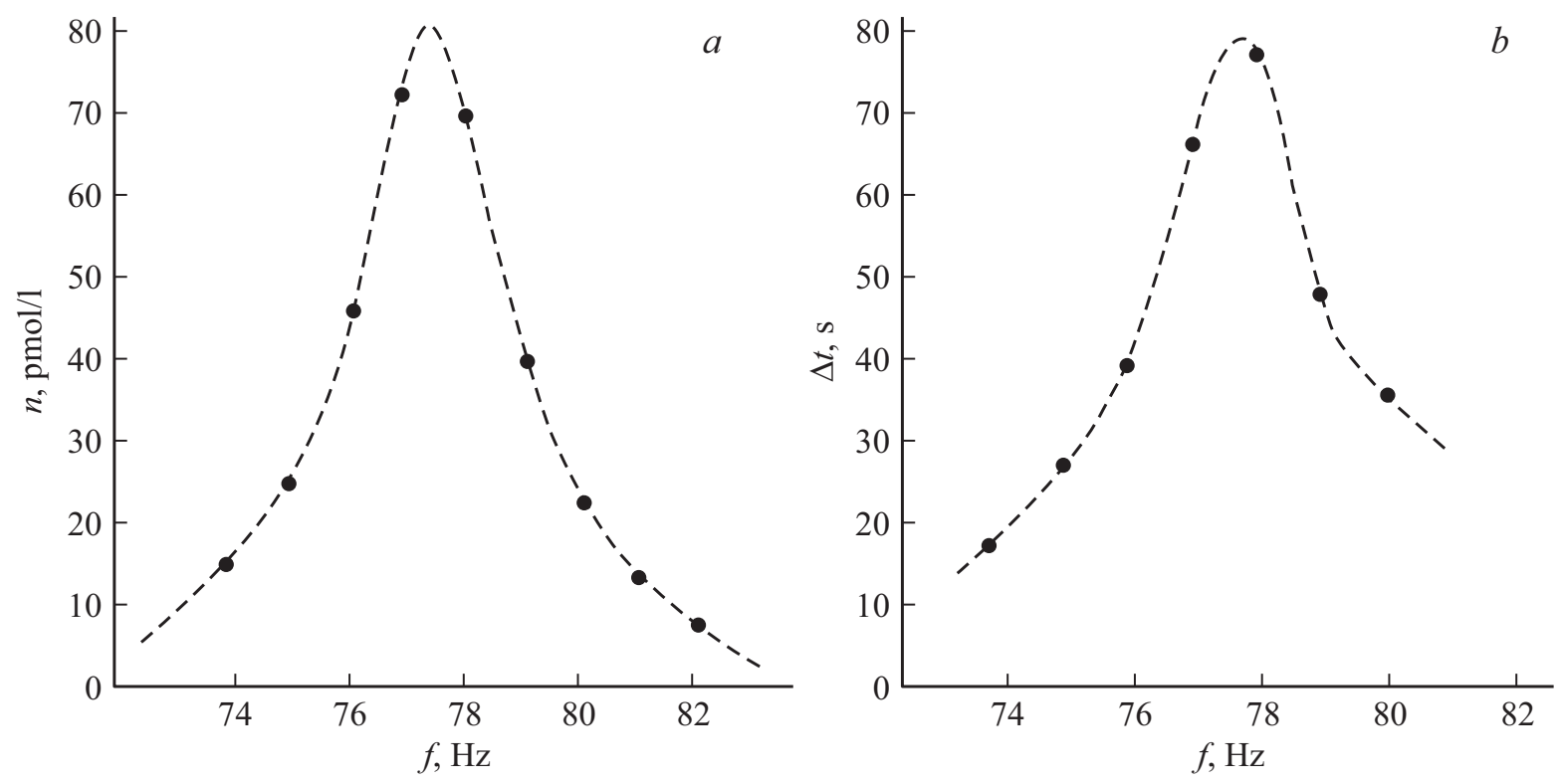

Рис. 4. $a$ - зависимость концентрации $n$ бета-эндорфинов (pmol/1) в спинномозговой жидкости кроликов от частоты стимулирующего тока. Эта частотная зависимость имеет резонансный характер, и резонанс достигнут на частотах 77-78 Hz [17]. $b$ - зависимость промежутка времени $\Delta t=t_{R}-t_{0}$ между моментом $t_{0}$ начала болевого термического раздражения и моментом $t_{R}$ импульсивной моторной реакции избегания животным болевого раздражения от частоты повторения импульсов ТЭС. Кривая достигает максимума на частотах $77-78 \mathrm{~Hz}$.

$N_{s t}=16$ (рис. 3, 3 ). Эффект подавления УР сохранялся в течение суток.

Животным четвертой группы через сутки после вживления электродов однократно вводился китрил, а через 30 min после введения китрила также осуществлялась ТЭС в течение $30 \mathrm{~min}$. Затем производилось многократное определение $N_{s t}$ в течение первых суток, через сутки, через двое суток и, наконец, через трое суток после введения китрила. График 4 на рис. 3,c показывает, что непосредственно после введения китрила ТЭС не способна увеличить $N_{s t}$ от 8 до 16 , как это происходило в группе без китрила, т.е. китрил блокирует результат ТЭС мозга животного, состоящий в торможении выработки УР. Эксперимент также показал постепенное исчезновение блокирующего действия китрила. По истечении суток действие китрила практически исчезало, и ТЭС статистически значимо увеличивала $N_{s t}$ до его численного значения $N_{s t}=16$, как в группе животных без китрила.

Таким образом, приведенные результаты свидетельствуют о том, что ТЭС мозга препятствует формированию УР. Китрил частично блокирует чувствительность серотонинэргических рецепторов, что проявляется в более быстром формировании УР даже на фоне ТЭС мозга.

На основании приведенных результатов можно считать доказанным, что процесс блокировки способности к выработке УР обусловлен воздействием на серотонинэргические рецепторы мозга повышенных доз серотонина, выработанных под воздействием ТЭС, поскольку введение китрила дезактивирует процесс перевозбуждения серотонинэргических рецепторов $[15,16]$. Эксперименты показали также, что вырабатываемый в процессе ТЭС серотонин влияет лишь на процесс выработки УР, затрудняя его, но не препятствует сохранению УР во времени. Конкретно: через сутки после введения китрила эффект блокады серотонинэргических рецепторов исчезал, и ТЭС вновь статистически достоверно увеличивала число сочетаний условного раздражителя и безусловного подкрепления, необходимых для образования устойчивой рефлекторной реакции.

\section{2. ТЭС мозга кроликов}

Прямыми измерениями регистрировалось изменение концентрации бета-эндорфинов в зависимости от рабочей частоты ТЭС. Рис. 4, $a$ показывает, что максимум концентрации отмечается при использовании частоты $78 \mathrm{~Hz}$ в стандартном приборе TESA [17]. Этот результат был подтвержден нами с помощью нового прибора с интерференционным алгоритмом воздействия, использующего для получения интерференции частоты 68 и $88 \mathrm{~Hz}$. Результатами экспериментов по снижению при ТЭС болевой чувствительности у кроликов является выявление зависимости времени $\Delta t(f)=t_{R}-t_{0}$ между моментом $t_{0}$ начала болевого раздражения и моментом $t_{R}$ моторной реакции избегания кроликом болевого раздражения от рабочей частоты модулирующего напряжения, имеющей вид резонансной кривой с максимумом на частоте $78 \mathrm{~Hz}$ (рис. $4, b$ ).

Эксперименты на второй и третьей группах кроликов показали, что наиболее выраженный анальгетический 

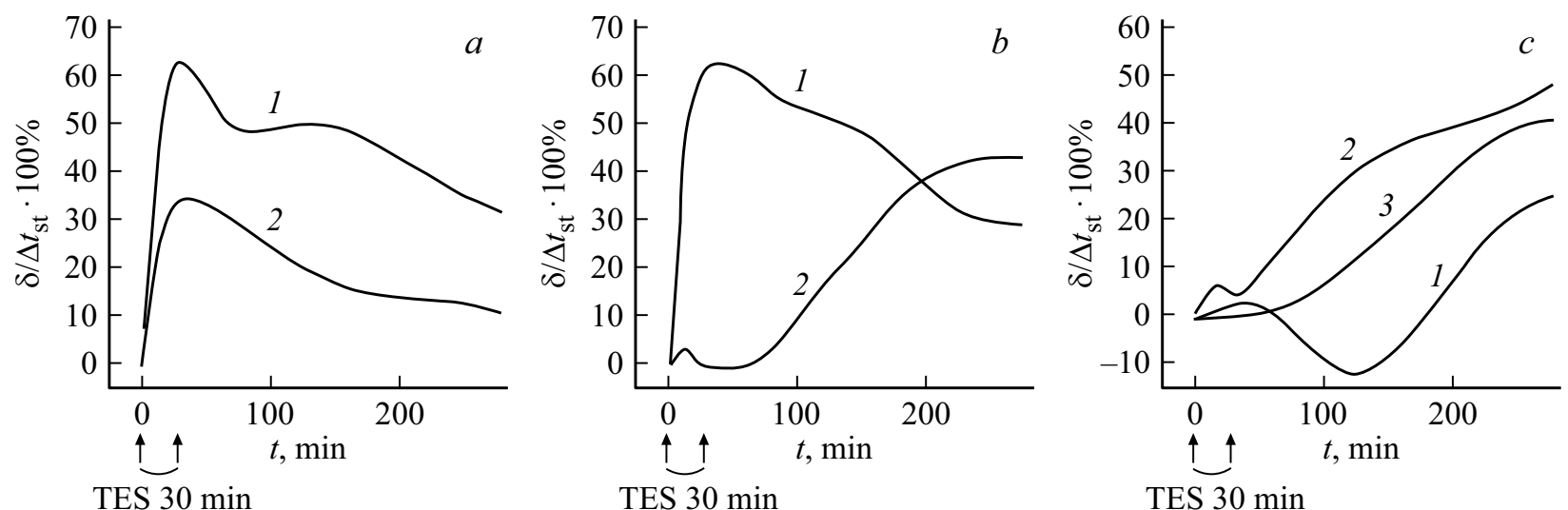

Рис. 5. Временная зависимость для кроликов величины $\delta(t) / \Delta t_{s t}$, где $\delta(t)=\Delta t-\Delta t_{s t}$ - отличие времени $\Delta t$ моторной реакции избегания кроликом болевого раздражения при ТЭС от времени $\Delta t_{s t}$ реакции избегания в обычных условиях без ТЭС. $a-$ сравнение зависимостей $\delta(t) / \Delta t_{s t}$ для четырехэлектродных интерференционных приборов с частотами 68 и $88 \mathrm{~Hz}$ (кривая 1 ) и 34 и $44 \mathrm{~Hz}$ (кривая 2). $b$ - временная зависимость $\delta(t) / \Delta t_{s t}$ после ТЭС для кроликов без введения налоксона (кривая 1$)$ и с введенным налоксоном (кривая 2). Этот результат получен с помощью модифицированного интерференционного прибора, снабженного системой автоматического регулирования напряжения для поддержания постоянства среднего тока. Система компенсирует рост электрического сопротивления мозга на начальном этапе воздействия ТЭС и его уменьшение на последующем этапе. Видно, что ТЭС увеличивает время реакции (болевой порог), которое после ТЭС с течением времени постепенно уменьшается. Наоборот, после введения налоксона время реакции мало (болевой порог низкий), несмотря на наличие ТЭС. После прекращения ТЭС время реакции постепенно увеличивается по мере снижения действия налоксона. $c$ - временная зависимость $\delta(t) / \Delta t_{s t}$ после ТЭС для кроликов с введенным налоксоном (кривая 1) и без налоксона (кривая 2) для ТЭС модифицированным интерференционным прибором и кривая 3 для ТЭС прибором TESA.

эффект возникал при использовании узкого диапазона частотных характеристик $(68 \pm 1)$ и $(88 \pm 1) \mathrm{Hz}$ (значение полусуммы частот равно $78 \mathrm{~Hz}$ ). Отклонение в любую сторону от заявленных параметров более чем на $2 \mathrm{~Hz}$ статистически значимо снижало обезболивающий эффект.

Данные, приведенные на рис. 5, $a$, соответствуют результатам, полученным с помощью ТЭС мозга кроликов двумя приборами с интерференционным алгоритмом воздействия: прибора, работающего на частотах 88 и $68 \mathrm{~Hz}$, и прибора, работающего на частотах 44 и $34 \mathrm{~Hz}$. Эти результаты отражают изменение во времени относительной величины $\delta(t) / \Delta t_{s t}(\%)$, где $\delta(t)=\Delta t-\Delta t_{s t}-$ отличие времени $\Delta t$ моторной реакции избегания кроликом болевого раздражения при ТЭС от времени $\Delta t_{s t}$ реакции в обычных условиях без ТЭС. Видно, что в первую минуту после начала ТЭС, когда стимуляции еще практически нет, $\delta(t) / \Delta t_{s t}=0$. По истечении $30 \mathrm{~min}$ ТЭС мозга на частотах 88 и $68 \mathrm{~Hz}$ величина $\delta(t) / \Delta t_{s t}$ возрастает до $65 \%$ по сравнению с обычным временем $\Delta t_{s t}$ реакции без ТЭС (кривая 1 на рис. $5, a$ ). В этот момент ТЭС выключается и производится наблюдение за изменением $\delta(t) / \Delta t_{s t}$ во времени. Кривая 1 показывает, что эффективность ТЭС мозга постепенно снижается: через $5 \mathrm{~h} \delta(t) / \Delta t_{s t}$ уменьшается с 65 до $30 \%$. Кривая 2 описывает аналогичные результаты ТЭС для прибора, работающего на частотах 44 и $34 \mathrm{~Hz}$ с той лишь разницей, что эффективность действия этого прибора примерно в 2 раза ниже.
В четвертой группе кроликов (рис. 5,b,c) исследовалось действие налоксона - блокатора бетаэндорфинэргических рецепторов мозга. Эксперименты в четвертой группе кроликов проводились на основании возникшего предположения о том, что если после введения налоксона ТЭС не будет приводить к увеличению времени избегания, т.е. не приведет к повышению болевого порога, то механизм анальгетического действия ТЭС основан на активации под влиянием ТЭС эндорфинэргических структур мозга. Данное предположение основано на том, что, согласно литературным данным [16], налоксон является антагонистом чувствительности бетаэндорфинэргических рецепторов мозга, и потому он способен блокировать чувствительность этих рецепторов и развитие анальгетического эффекта, который возникает при ТЭС из-за роста генерации бетаэндорфина в структурах мозга.

Кривая 1 на рис. 5, $b$, аналогичная кривой 1 на рис. 5, $a$, демонстрирует эффективность ТЭС мозга (величина $\delta(t) / \Delta t_{s t}$ составляет несколько десятков процентов) и приведена здесь для сравнения с кривой 2. Кривая 2 на рис. 5, $b$ соответствует случаю введения в брюшину животного налоксона при одновременном включении ТЭС на частотах 88 и $68 \mathrm{~Hz}$. В первые $10 \mathrm{~min}$ наблюдается рост запаздывания моторной реакции до значения $\delta(t) / \Delta t_{s t}=7 \%$ от стандарта, а затем начинается его спад, что обусловлено активизацией блокирующего действия налоксона. К моменту выключения ТЭС $\delta(t) / \Delta t_{s t}$ падает, проходя через минимум в $2 \%$. После этого фиксируется медленный рост времени запазды- 
вания моторной реакции, доходящий через несколько часов до $45 \%$ от стандарта, что связано с постепенным исчезновением блокирующего действия налоксона.

Рис. 5, с демонстрирует сравнение степени блокирующего воздействия налоксона на три группы животных: без ТЭС - кривая 1 , подвергавшихся интерференционной ТЭС на частотах $88 \mathrm{~Hz}$ и $68 \mathrm{~Hz}$ - кривая 2 и трехэлектродной ТЭС без интерференции на частоте $78 \mathrm{~Hz}$ - кривая 3. Кривые 2 и 3 на рис. 5, с аналогичны кривой 2 на рис. 5, $b$, причем они показывают, что ТЭС без интерференции демонстрирует по сравнению с интерференционным ТЭС существенно меньшую устойчивость к блокирующему действию налоксона, несмотря на то, что средний ток для нее вдвое больше, чем при использовании интерференции. Ход кривой 1 (в отсутствие ТЭС) показывает, что после введения налоксона задержка моторной реакции на болевое воздействие падает по отношению к стандартной, так что разность $\delta(t)=\Delta t-\Delta t_{s t}$ становится отрицательной, поскольку $\Delta t<\Delta t_{s t}$ из-за налоксона. Это указывает на изначальную выработку в организме здорового животного некоторой обычной концентрации бетаэндорфинов, определяемой стандартным гомеостазом. Через $2 \mathrm{~h}$ запаздывание $\Delta t$ достигает минимума, а величина $\delta(t) / \Delta t_{s t}$ достигает минимального отрицательного значения - $12 \%$. По мере снижения концентрации налоксона время запаздывания $\Delta t$ не только возвращается (через $3 \mathrm{~h}$ ) к стандартному значению $\Delta t_{s t}(\delta(t)=0)$, но и начинает превышать его, причем через $5 \mathrm{~h}$ величина $\delta(t) / \Delta t_{s t}=25 \%$.

Таким образом, эксперимент подтвердил, что применение налоксона приводит к статистически значимой блокировке развития анальгетического эффекта, который восстанавливается после прекращения действия налоксона, т. е. получено подтверждение предположения о наиболее эффективной активации эндорфинэргических структур мозга при использовании интерференционного алгоритма ТЭС и обеспечении этим анальгетического эффекта.

\section{3. Обсуждение результатов}

Полученные в настоящей работе результаты можно связать с современными представлениями о механизмах формирования УР и подавления безусловного рефлекса.

\section{1. Формирование УР}

Формирование УР у крыс предполагает создание устойчивой связи в мозге между окончаниями двух нервных цепей: восприятия звукового и тактильного воздействий (звонка и электроудара). При взаимодействии этих цепей передача сигнала внутри мозга от одной цепи к другой может осуществляться как через сенсоры внешнего восприятия, так и через внутреннее воздействие, возникающее при непосредственном точечном контакте дендритов одной цепи с нейронами другой цепи. Осуществляется передача сигнала между обеими цепями с помощью нейротрансмиттерных везикул, выделяющих нейромедиаторы (выделяемые везикулой активные вещества, активирующие формирование электрического отклика клеточных рецепторов дендрита) в синаптическую щель (микрометровый зазор между нейротрансмиттерной везикулой - окончанием аксона - и дендритом), т.е. передачу сигнала от внесинаптических рецепторов нейронов тактильной цепи к дендритам нейронов звуковой цепи.

При выработке УР образуется новая временная связь между корковыми отделами слухового анализатора в мозге и центральным звеном безусловного рефлекса [18], т. е. образуется рефлекторная дуга (рефлекторное кольцо [19]), состоящая из следующих элементов: звуковые рецепторы (сенсоры), афферентное звено (нервный путь от звукоприемника в центральную нервную систему), центральное звено (нервный путь, связывающий слуховой центр мозга с нервным центром мозга, отвечающим за сохранение информации о безусловных рефлексах), эфферентное звено (нервный путь, связывающий структуру, ответственную за наличие безусловных рефлексов с исполнительным органом), эффектор исполнительный орган (мышцы). Безусловный рефлекс в отличие от УР - это выработанная эволюцией устойчивая связь между рецепторами (сенсорами) внешнего воздействия и эффектором. При формировании УР происходит активация структур синаптического аппарата, приводящая к появлению нового канала передачи информации по временной рефлекторной дуге (кольцу).

Обычно стандартный пропорциональный сенсор имеет S-образную характеристику, т.е. обладает порогом чувствительности, линейным участком передаточной характеристики и областью насыщения чувствительности. Поэтому мы считаем, что генерируемый при ТЭС серотонин вводит в режим насыщения синаптические рецепторы звука (действующие аналогично сенсору), связанные с афферентным и далее с центральным звеном, затрудняя их функционирование. ТЭС не подавляет полностью, как показывает эксперимент (кривые 3, 4 на рис. 3, ), выработку УР, а лишь затрудняет ее, оставляя почти нетронутым внутрищелевой нейротрансмиттерный механизм линии центральное звено-эфферентное звено-эффектор. Разумеется, некоторый взаимообмен нейромедиаторами между внутрищелевыми и внещелевыми рецепторами все же происходит [19].

Китрил, являясь ингибитором серотонина, адсорбируется на поверхности мембран свободных внешних рецепторов слуховой нейронной цепи [20,21], сдвигая их потенциал в положительную сторону настолько, чтобы заблокировать процесс взаимодействия серотонина с этими рецепторами. При этом процесс взаимодействия нейротрансмиттеров с рецепторами не затруднен, так как их потенциал действия еще выше. Благодаря обмену между внешними и внутрищелевыми рецепторами действие китрила, блокирующее перенасыщение рецепторов серотонином, распространяется за время 
30 min на всю рефлекторную дугу (кольцо). Тормозящее выработку УР действие сероонина, вырабатываемого во время ТЭС, прекращается, что и наблюдается в эксперименте. С другой стороны, китрил как блокатор или ингибитор (в отличие от катализатора) непрерывно расходуется [21] и выводится из организма, и спустя сутки он перестает блокировать тормозящее выработку УР действие серотонина, что наблюдается на опыте в виде возобновления торможения выработки УР при ТЭС (рис. 3,c).

\section{2. Механизм подавления безусловного рефлекса}

Механизм подавления безусловного рефлекса для кроликов заключается в следующем. В организме кролика уже существует устойчивая связь между рецепторами тактильного воздействия и эффектором. Моторная реакция избегания болевого раздражения характеризуется естественным временем, за которое сигнал проходит этот путь. ТЭС мозга животных активирует генерацию не только серотонина, но и бета-эндорфинов. Поэтому ТЭС мозга кроликов так же, как и серотонин, перенасыщает эндорфинэргические рецепторы нейронов, тормозя их работу. На опыте это приводит к увеличению времени моторной реакции кролика на болевое раздражение (рис. 6, $a$, кривая 1). Инъекция налоксона за $30 \mathrm{~min}$ до начала ТЭС воздействует на внешние эндорфинэргические рецепторы, сдвигая их потенциал настолько, чтобы блокировать действие бета-эндорфинов. Через $30 \mathrm{~min}$ за счет обмена между внесинаптическими и синаптическими рецепторами действие налоксона распространяется на все нейроны нервной цепи, которая обеспечивает срабатывание безусловного рефлекса избегания болевого раздражения. Налоксон, как и китрил, является ингибитором и расходуется в процессе химической реакции взаимодействия с рецепторами. Поэтому через несколько часов его влияние прекращается, что проявляется на опыте в виде возобновления при ТЭС увеличения времени моторной реакции на болевое раздражение (снижения болевой чувствительности) (рис. 5, $a$, кривая 2).

Следует отметить, что введение налоксона без последующего проведения ТЭС мозга кролика приводит к уменьшению времени моторной реакции избегания болевого раздражения (росту болевой чувствительности). Дело в том, что организм животного в обычных условиях производит некоторое количество бетаэндорфина, обеспечивая естественное время избегания. Введение ингибитора - налоксона - блокирует небольшое тормозящее действие бета-эндорфина обычной концентрации, в результате чего время моторной реакции сокращается. Эксперимент по введению налоксона (кривая 3 на рис. 5,c) подтверждает также то, что передача нервных импульсов по нейронной цепи не нарушается ингибитором бета-эндорфина, т.е. налоксон не блокирует действие нейромедиаторов, необходимых для передачи нервных импульсов.

\section{4. Техническая сторона предложенного метода}

- ТЭС мозга дает ярко выраженные результаты при использовании импульсного электромагнитного воздействия в отличие от использования синусоидального воздействия. Дело в том, что внешний электромагнитный импульс при воздействии на биологическую систему запускает каскад электрохимических реакций, каждая из которых характеризуется своим характерным временем. Так, потенциал действия нейрона состоит из нескольких фаз и длится несколько ms, причем первая фаза, начало которой определяется порогом срабатывания, имеет длительность менее $1 \mathrm{~ms}$ [22] (рис. 6).

Поэтому импульсное электрическое воздействие, с одной стороны, запускает формирование потенциала действия нейрона, а с другой стороны, из-за высокой крутизны переднего фронта, создает возможность последовательного протекания для всех фаз активации потенциала действия без каких бы то ни было помех. Непосредственно после завершения всего каскада реакций внешнее электрическое воздействие меняет полярность также с высокой крутизной заднего фронта импульса, что увеличивает интенсивность и длительность следовой гиперполяризации (запоминаемого электрического отклика нейрона) [22], давая возможность нейрону продлить период гиперполяризации до прихода следующего импульса ТЭС. Поэтому понятно, что импульс длительностью, меньшей $0.1 \mathrm{~ms}$, никаких эффектов не вызывает [23]. Длительность импульса в наших экспериментах составляла $12 \mathrm{~ms}$, что больше времени активации потенциала действия нейрона. В то же время синусоидальное напряжение, ввиду постепенности нарастания величины напряжения, не обеспечивает запуска

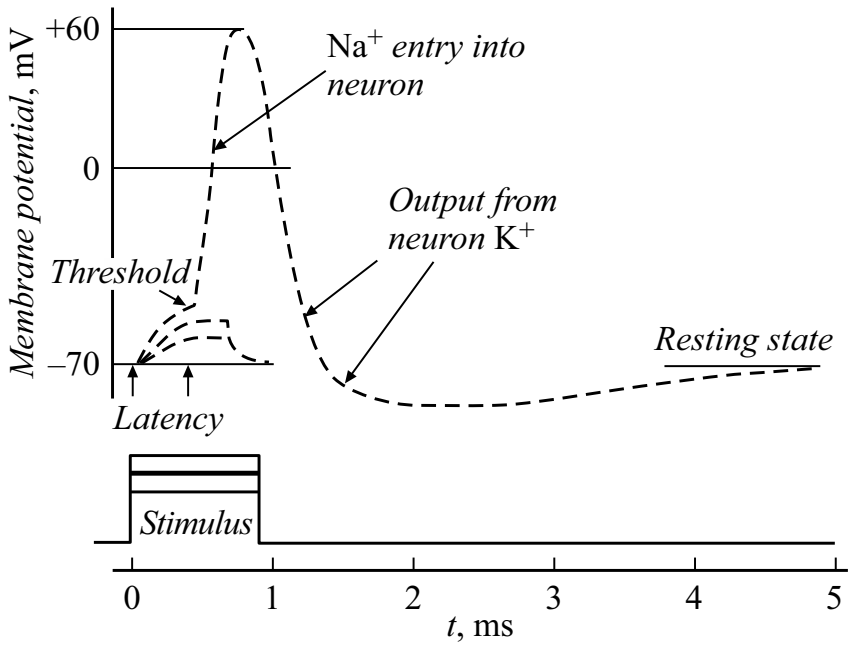

Рис. 6. Потенциал действия нейрона [22]. 


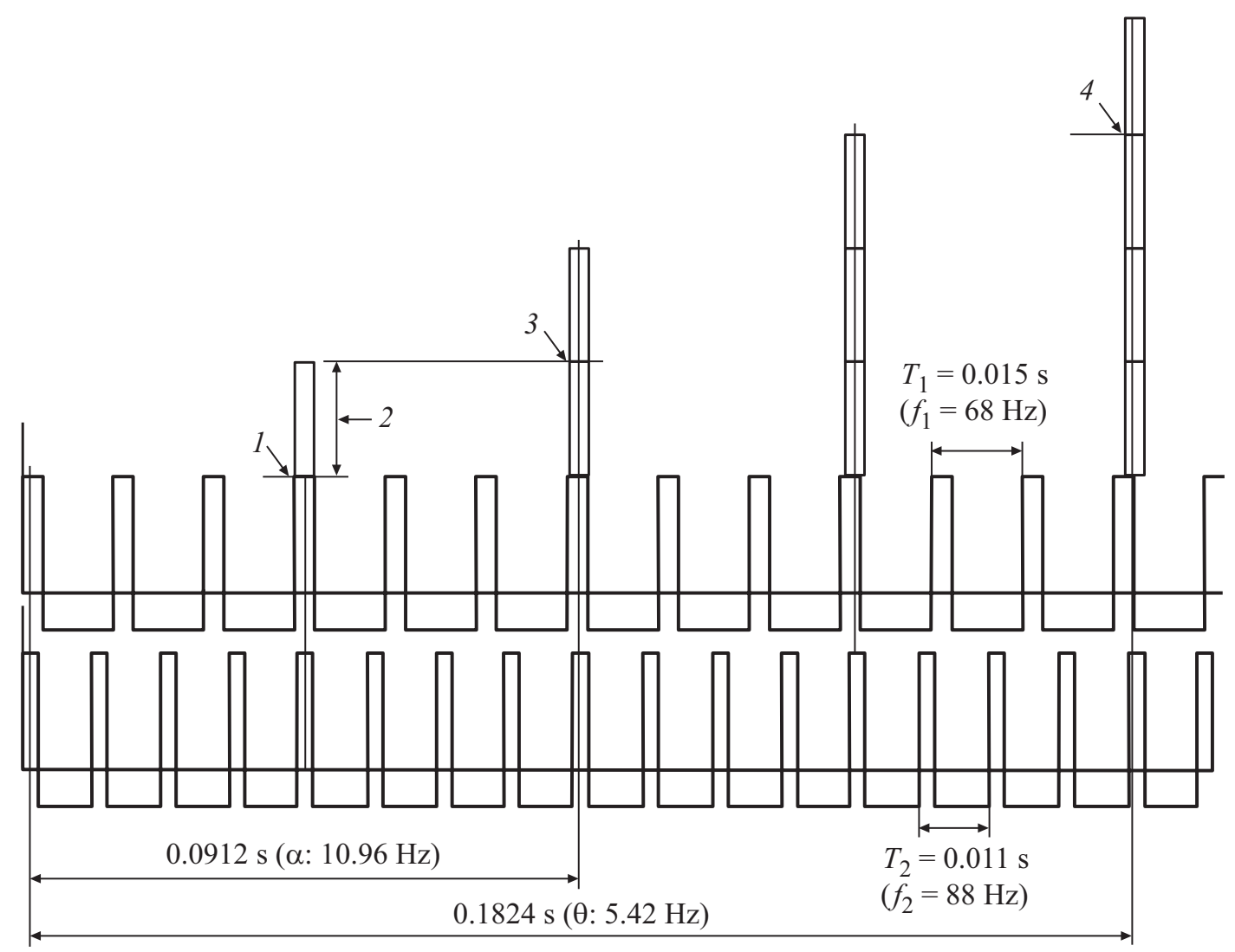

Рис. 7. Сложение импульсов 68 и $88 \mathrm{~Hz}$.

электрохимических реакций, имеющих резко пороговый характер активации [24]

- ТЭС мозга имеет „резонансный“ характер, т. е. эффективна на частоте модуляции $(78 \pm 2) \mathrm{Hz}$. Объяснение этого факта сводится к следующему. Поскольку нейрон обладает способностью к запоминанию электровоздействия (что точно установлено [25]), приход следующего импульса должен осуществляться до того момента, когда нейрон полностью „забудет“ свое состояние, т.е. период возбуждения должен быть меньше времени ,забывания“. Это диктует необходимость применения строго определенной частоты повторения импульсов. В нашем случае это соответствует частоте $78 \mathrm{~Hz}$. Кроме того, как показывает проведенный нами фурье-анализ, только последовательность импульсов максимальной крутизны фронтов и частоты $78 \mathrm{~Hz}$ обеспечивает бо́льшую амплитуду фурье-гармоник в области низких частот $(5-10 \mathrm{~Hz})$, совпадающих с частотами $\alpha$ - и $\theta$-ритмов мозга.

- ТЭС мозга в новом четырехэлектродном варианте прибора имеет вдвое более высокую эффективность используемого в нем интерференционного алгоритма по сравнению с трехэлектродным вариантом прибора TESA [17]. Причина в том, что, согласно [25], ТЭС мозга на частотах $5-10 \mathrm{~Hz}$, совпадающих с частотами $\alpha$ - и $\theta$-ритмов мозга, также приводит к эффективной генерации серотонина и бета-эндорфина, вдвое усиливая эффективность ТЭС, запуская дополнительный каскад электрохимических реакций за счет эффекта запоминания подпорогового состояния [26].

- ТЭС мозга на частоте $78 \mathrm{~Hz}$ может активировать потенциал действия нейрона на более низких частотах. Это связано с тем, что нейрон имеет порог срабатывания, и если амплитуда возбуждающего импульса меньше этого порога, то запуск электрохимических реакций в нейронной цепи не происходит, однако факт прихода импульса ниже порога нейроном запоминается (позиции 1,2 на рис. 7). При поступлении последующих импульсов в результате их взаимного сложения происходит запуск формирования потенциала действия нейрона, но уже под действием импульсов низкой частоты. Частота эта определяется совпадением во времени моментов прихода импульсов частот 88 и $68 \mathrm{~Hz}$. Например, если каждый седьмой импульс частоты $68 \mathrm{~Hz}$ совпадает с каждым девятым импульсом частоты $88 \mathrm{~Hz}$ (позиция 3 на рис. 7) и вызывает запуск, то временной интервал между совпадающими импульсами соответствует частоте $10 \mathrm{~Hz}$, т.е. $\alpha$-ритму мозга. Если другие совпадения дают суммарную амплитуду ниже порога срабатывания, то в этом случае нейрон функционирует как запоминающий делитель частоты. Если имеет место совпадение 13-го и 17-го импульсов (позиция 4 на рис. 7), то это соответствует $\theta$-ритму мозга. 
- Амбиполярная форма импульсов ТЭС подавляет судорожную активность мышщ. Возникновение судорожной активности объясняется следующим образом. Клеточная мембрана нейрона соприкасается с большим количеством присутствующих в ликворе ионов $\mathrm{Na}^{+}$, $\mathrm{K}^{+}$и $\mathrm{Cl}^{-}$. Под влиянием внешнего электрического воздействия в виде низкочастотного переменного тока симметричной формы (применявшегося в ранних модификациях ТЭС аппаратуры), которое носит резонансный характер, усиливается диффузия ионов $\mathrm{Na}^{+}$через натриевые каналы внутрь нейрона, в результате чего снижается отрицательный внутренний заряд, на что нейрон реагирует лавинной деполяризацией и актом выброса электрического импульса в нейронную сеть. После этого равновесный потенциал восстанавливается (реполяризация) [16]. Если внутрь клетки при симметричном импульсном электровоздействии поступит избыточное количество ионов натрия и будет достигнут пороговый уровень компенсации отрицательного внутреннего заряда с переходом его в зону положительных значений, то случится „залповая““ деполяризация нейрона - импульсный ответ нейрона на критическое значение разности потенциалов между внутренней и наружной поверхностями мембраны [22]. Произойдет перевод нормально функционирующих нейронов в пейсмейкерные - генерирующие неуправляемые нервные импульсы [26]. Нейроны начнут генерировать импульсы самопроизвольно, посылая в нервную сеть серию „незапланированных“ нервных импульсов. Доходя по нервным путям до центров управления мышечной активностью животного, эти импульсы спровоцируют судорожную патологическую активность.

Подавление судорожной активности обеспечивается последовательностью несимметричных амбиполярных импульсов, что обусловливает, как указывалось выше, протекание постоянной составляющей тока между электродами. Дело в том, что при пропускании через мозг, наряду с переменным, постоянного тока происходит направленное перемещение ионов натрия и хлора, входящих в состав ликвора базальных цистерн мозга. Постоянный ток организует два встречных потока ионов противоположных знаков, причем создает преимущественное увлечение всего жидкостного массива в пользу ионов $\mathrm{Cl}^{-}$ввиду большего миделевого сечения гидратных оболочек ионов $\mathrm{Cl}^{-}$и квадратичной зависимости стоксовой силы от скорости течения. Поперечник гидратных оболочек отрицательных ионов $\mathrm{Cl}^{-}$сильно превышает [27] поперечник положительных ионов $\mathrm{Na}^{+}$, так как они образуются за счет водородных связей крупных отрицательных ионов $\mathrm{Cl}^{-}$с молекулами воды. Возникает однонаправленный поток жидкости ввиду резкой разницы миделевых сечений ионных конгломератов. При этом поток жидкости выводит, согласно уравнению Бернулли, ионы $\mathrm{Na}^{+}$из устьев натриевых каналов в процессе, аналогичном процессу работы водоструйного насоса. Этот эффект затрудняет пресыщение внутренних полостей нейронов положительными зарядами $\mathrm{Na}^{+}$, не доводя мембранный потенциал до порогового значения $(+60 \mathrm{mV})$, блокируя спонтанную деполяризацию и предотвращая этим генерацию импульсов судорожной активности.

- И, наконец, использование интерференционного алгоритма ТЭС подавляет эффект „привыкания“. Это связано с тем, что сложный вид годографа векторов суммарных токов и электромагнитных полей (рис. 2,a) приводит к непрерывной смене групп активируемых нейронов, предотвращая эффект привыкания нейронов к процессу ТЭС.

\section{Заключение}

В работе установлено, что активация выработки серотонина и эндорфинов в структурах мозга обусловлена не только активацией серотонинэргических и эндорфинэргических структур мозга ТЭС на частоте $78 \mathrm{~Hz}$, но и связана также с резонансным усилением $\alpha$ - и $\theta$-волн мозга, способных вызывать нейромодулирующий эффект. Это оказывается возможным в результате возникновения фурье-гармоник с частотами 10 и $5 \mathrm{~Hz}$ при использовании интерференционного импульсного алгоритма ТЭС. Вызванный резонансной активацией рост амплитуды $\alpha$-волн обусловливает увеличение концентрации бетаэндорфинов, в результате чего уменьшается стрессорное воздействие на организм, в частности, связанное с болью.

Максимальная степень подавление УР у крыс и максимальный обезболивающий эффект, который оценивался у кроликов по реакции избегания термического воздействия (болевой порог) отмечались при использовании ТЭС частоты $78 \mathrm{~Hz}$. В предложенном нами транскраниальном электромагнитном стимуляторе такая частота формировалась в результате использования токов высокой частоты, промодулированных меандрами с частотами 88 и $68 \mathrm{~Hz}$. Подчеркнем, что для достижения с помощью модифицированного стимулятора мозга результатов, эквивалентных результатам, даваемым прибором предшествующей конструкции, требуется использование вдвое меньшего тока $(0.1 \mathrm{~mA}$ по сравнению с $0.2 \mathrm{~mA}$, рис. $5, c)$.

Принципиально важно, что как подавление способности крыс к выработке УР, так и повышение болевого порога у кроликов вызваны интерференционными биениями, возникающими в предложенном ТЭС-приборе в зоне пересечения взаимно перпендикулярных трубок токов. При этом отсутствие у животных судорог, ранее возникавших при ТЭС, обусловлено протеканием через мозг животного постоянного тока, возникающего в результате частичного выпрямления переменной высокочастотной составляющей $(500 \mathrm{kHz})$ благодаря вентильным свойствам системы „электрод-мозг-электрод“. 


\section{Соблюдение этических норм}

Все применимые международные, национальные и/или институциональные принципы ухода и использования животных были соблюдены.

\section{Благодарности}

Авторы благодарят за содействие и консультационную помощь Н. Beckhoff and V. Chuev (Brain Advance Wellness Technologies, 3801 Stump Rd, Doylestown, PA 18902, USA).

\section{Конфликт интересов}

Авторы заявляют, что у них нет конфликта интересов.

\section{Список литературы}

[1] A. Wood, R. Mate, K. Karipidis. J. Exposure Sci. Environmental Epidemiolology, 16, 1 (2021). DOI:10.1038/s41370-021-00307-7

[2] В.Н. Бинги, А.В. Савин. УФН, 173 (3), 265 (2003).

[3] В.Н. Бинги. Принщипь электромагнитной биофизики (Физматлит, М., 2011)

[4] V.P. Lebedev, Y.S. Katsnelson. Transcranial Electric Simulation: Analgesia and Allied Effects. In: Automatization in Physiological Investigations (Leningrad, Nauka, 1988), p. 198.

[5] А.О. Вонти, А.В. Ильинский, Я.С. Кацнельсон, Е.Б. Шадрин. Письма в ЖТФ, 44 (17), 27 (2018).

[6] T. Brinker, E. Stopa, J. Morrison, P. Klinge. CNS, 11, 10 (2014). DOI:10.1186/2045-8118-11-10

[7] L.N. Airapetov, A.M. Zaitchik, M.S. Trukhmanov, V.P. Lebedev, V.A. Sorokoumov, Y.S. Katsnelson, V.G. Abisogomian, Y.K. Kodzayev. Fiziol. Zhurn. SSSR, 71 (1), 56 (1985).

[8] D.A. Gruenewald, A.M. Matsumoto. Hypothalamic Changes Relevant to Reproduction in Aging Male Rodents in Functional Neurobiology of Aging., ed. by P.R. Hof and Ch.V. Mobbs (Academic Press, 2000)

[9] V.P. Lebedev, Y.S. Katsnelson, V.A. Leosko, A.L. Baranovsky, G.I. Shiemis. Fiziol. Zhurn. SSSR, 59 (8), 1120 (1983).

[10] S.J. Van Albada, P.A. Robinson. Frontiers in Human Neuroscience, 7 (2013). DOI:10.3389/fnhum.2013.00056

[11] S.A. Chkhenkeli, M. Šramka, G.S. Lortkipanidze, T.N. Rakviashvili, E.S. Bregvadze, G.E. Magalashvili, I.S. Chkhenkeli. Clinical Neurology and Neurosurgery, 106 (4), 318 (2004). DOI:10.1016/j.clineuro.2004.01.009

[12] В.П. Лебедев, А.Б. Савченко, А.Б. Фан, С.Ю. Жиляев. Физиол. журн. СССР, 74 (8), 1094 (1988).

[13] A.S. Sprouse-Blum, G. Smith, D. Sugai, F. Don Parsa. Hawaii Med. J., 69 (3), 70 (2010).

[14] S. Maxwell, D. Bigg, K. Stanczykiewicz, S. Carlberg-Racich S.J. Addict Dis. J., 25 (3), 89 (2006). DOI:10.1300/J069v25n03_11

[15] А.С. Владыка, А.А. Шандра, Р.Е. Хома, В.М. Воронцов. Ноцицепция и антиноцищепция : теория и практика (ФОП „Каштелянов А.И.“, Винница, 2012)

[16] D.L. Nelson. CNS and Neurological Disorders, 3 (1), 53 (2004).
[17] Y. Katsnelson, H. Beckhoff, E. Berk, Y. Palkin, N. Lisyanskaya, A. Tereo, N. Baranova. Proceedins of VI-th International Regional (Asia) ISBS Neuroscience Conference „Stress and Behavior", p. 26.

[18] Н.Н. Данилова. Физиология высшей нервной деятельности (Феникс, Ростов-на-Дону, 2005)

[19] В.П. Дудьев. Психомоторика: словарь-справочник (Национальная психологическая энциклопедия, 2008)

[20] А.В. Семьянов, В.Б. Казанцев. Нейрон-глиальное взаимодействие в мозге. Учебно-методический материал по программе повышения квалификации „Хранение $u$ обработка информации в биологических системах (ННГУ, Нижний Новгород, 2007)

[21] Ингибиторы. Краткая химическая энщиклопедия, И.Л. Кнунянц (гл. ред.) (Сов. энциклопедия, M., 1961-1967), т. 2, c. 228-229.

[22] M. Lavzin, S. Rapoport, A. Polsky, L. Garion, J. Schiller. Nature, 490 (7420), 397 (2012), DOI: $10.1038 /$ nature 11451

[23] J. Malmivuo, R. Plonsey. Bioelectromagnetism (Oxford University Press, NY., Oxford, 1995)

[24] А.В. Савельев. Журнал проблем эволюции открытых систем, 8 (2), 96 (2006).

[25] B.N. Levy, B.M. Koeppen, B.A. Stanton. Principles of Physiology (Elsevier, 2005), p. 836.

[26] V.S. Sohal, F. Zhang, O. Yizhar, K. Deisseroth. Nature, 459 (7247), 698 (2009). DOI:10.1038/nature07991

[27] А.О. Вонти, А.В. Ильинский, В.М. Капралова, Е.Б. Шадрин. ЖТФ, 88 (6), 934 (2018). 